\title{
Rapid ground deformation of the Miyakejima volcano on 26-27 June 2000 detected by kinematic GPS analysis
}

\author{
Meilano Irwan ${ }^{1}$, Fumiaki Kimata ${ }^{1}$, Naoyuki Fujii ${ }^{1}$, Shigeo Nakao ${ }^{2}$, Hidehumi Watanabe ${ }^{2}$, Shinichi Sakai $^{2}$, \\ Motoo Ukawa ${ }^{3}$, Eisuki Fujita ${ }^{3}$, and Koji Kawai ${ }^{4}$ \\ ${ }^{1}$ Graduate School of Environmental Studies, Research Center for Seismology and Volcanology, Nagoya University, Nagoya, Japan \\ ${ }^{2}$ Earthquake Research Institute, University of Tokyo, Tokyo, Japan \\ ${ }^{3}$ National Research Institute for Earth Science and Disaster Prevention, Tsukuba, Japan \\ ${ }^{4}$ Japan Hydrographic Department, Marine Preservation, Tokyo, Japan
}

(Received February 28, 2003; Revised June 13, 2003; Accepted June 16, 2003)

\begin{abstract}
A kinematic GPS analysis of data from the Miyakejima volcano captured a fast developing deformation event on 26-27 June 2000 in unprecedented spatial and temporal detail. Initial ground deformation toward east and upward was observed in the southeastern part of the volcano at 18:00 on 26 June 2000, almost simultaneous with earthquake swarms. Some time after 21:30 on 26 June 2000 the displacements at these sites turned from eastward to westward. Three hours later the displacement rates increased gradually at GPS sites in the western part of Miyakejima as the seismicity migrated and approached the west coast, and reached a climax with submarine eruption at 09:00 on 27 June 2000. A Genetic Algorithm was used to explore the parameter space and to find the best fitting source geometry. This analysis leads to an interpretation that the 18:00 26 June earthquake swarm was caused by a dike intrusion near the Oyama crater. Starting from 21:30 this dike deflated and a new dike intruded near the west coast. Following the propagation of this dike to the offshore, a spherical source began deflating in the southwest of Oyama crater.
\end{abstract}

Key words: Miyakejima, rapid deformation, kinematic GPS.

\section{Introduction}

The Miyakejima volcano is an active stratovolcano lying on the Philippine Sea plate, part of the Izu-Bonin Arc. The last three eruptions before 2000 were in 1940, 1962, and 1983. Those eruptions began with precursory seismic activities which lasted for several hours. They were fissure eruptions on the NW or SE flanks (Fig. 1), although some summit eruptions are also known (Tsukui et al., 2001). When swarms of small volcanic earthquakes suddenly started beneath Miyakejima's western flank on 26 June 2000, volcanologists were very anxious about the possibility of an eruption. However, the 2000 eruption was different from the previous ones in many respects. It started with swarms at about 18:30 Japan Standard Time (JST = GMT + 9). Approximately three hours after the swarm began, seismicity migrated to the area between the western flank of Miyakejima and the west coast. By 23:30, the earthquake swarm had reached the west coast of Miyakejima Island. At 9 a.m. on 27 June 2000, a small submarine eruption, which ejected $5 \times 10^{-6} \mathrm{~km}^{3}$ of material, occurred $1.5 \mathrm{~km}$ off the west coast of Miyakejima (Shirao et al., 2000). After this eruption the earthquake swarm moved further northwestward towards Kozushima Island (Nishimura et al., 2001).

On 1 July an $\mathrm{M}_{\mathrm{JMA}} 6.4$ earthquake occurred near Kozushima island and many earthquakes were observed in the area between Kozushima Island and the Miyakejima Is-

Copy right(C) The Society of Geomagnetism and Earth, Planetary and Space Sciences (SGEPSS); The Seismological Society of Japan; The Volcanological Society of Japan; The Geodetic Society of Japan; The Japanese Society for Planetary Sciences. lands. Ground deformations of more than $30 \mathrm{~cm}$ were also observed in Kozushima Island by continuous GPS measurements (JMA, 2000) and were modeled as resulting from intrusion of large dike over $1 \mathrm{~km}^{3}$ between the Miyakejima and Kozushima Islands (Kaidzu et al., 2000; Yamaoka et al., 2001). During the great dike intrusion between the Kozushima and Miyakejima Islands, Miyakejima volcano erupted on 10 July, 18, and 30 August. The eruption column of 18 August reached to a height of $18 \mathrm{~km}$. Strikingly, before this large eruption, a summit caldera $1 \mathrm{~km}$ wide formed and volcanic gas spouted from the caldera on a massive scale. Mass balance considerations suggest that a large amount of magma migrated $30 \mathrm{~km}$ from Miyakejima toward Kozushima Island (Nishimura et al., 2001).

Ground deformation has long been observed to monitor the activity of the Miyakejima volcano, dating from the first leveling survey in 1979. The leveling data has revealed inflation prior to eruption, deflation associated with it, and reinflation after that in 1983 (Tada and Nakamura, 1988). GPS measurements at Miyakejima began in 1990 with campaignstyle observations. The network has been used for yearly observations since 1995 and has revealed 2-3 cm/yr inflation in the western part of Miyakejima (Kariya et al., 2000). Furthermore, using rapid static GPS analysis from August 1999 to 1 July 2000, Oikawa et al. (2000) detected large deflation near the Oyama crater.

In this study, we processed GPS data from Miyakejima using a kinematic GPS analysis with a time interval of $30 \mathrm{sec}$. The data started from 12:00 26 June 2000, before the earth- 
Table 1. Estimated parameter and uncertainties.

\begin{tabular}{|c|c|c|c|c|}
\hline Parameter & Phase 1 & Phase 2 & & Phase 3 \\
\hline Length (km) & $-0.351 .2^{+0.35}$ & $-0.51 .2^{+0.5}$ & $-0.41 .3^{+0.4}$ & $-0.351 .8^{+0.35}$ \\
\hline Width $(\mathrm{km})$ & $-0.52^{+0.5}$ & $-0.82^{+0.8}$ & $-0.82 .2^{+0.8}$ & $-1.25 .5^{+1.2}$ \\
\hline Depth to top (km) & $-0.10 .3^{+0.5}$ & $-0.10 .3^{+0.8}$ & $-0.250 .66^{+0.24}$ & $-0.20 .65^{+0.2}$ \\
\hline Dip (deg) & $-1240^{+12}$ & $-1440^{+40}$ & $-1089^{+10}$ & $-0.585^{+5}$ \\
\hline Strike (deg) & $-1553^{+15}$ & $-{ }^{-10} 53^{+10}$ & ${ }^{-12} 117^{+12}$ & ${ }^{-5} 117^{+5}$ \\
\hline Lat. (deg) & $-0.00434 .076^{+0.004}$ & $-0.00834 .076^{+0.008}$ & $-0.00434 .076^{+0.004}$ & $-0.00434 .083^{+0.004}$ \\
\hline Long. (deg) & $-0.004139 .509^{+0.004}$ & $-0.009139 .509^{+0.009}$ & $-0.006139 .492^{+0.006}$ & $-0.004139 .47^{+0.004}$ \\
\hline Opening (m) & $-0.51 .9^{+0.5}$ & $-0.50 .9^{+0.5}$ & $-0.51 .8^{+0.5}$ & $-0.54 .4^{+0.5}$ \\
\hline Lat. (deg) & & & & $-0.00834 .067^{+0.008}$ \\
\hline Long. (deg) & & & & $-0.009139 .508^{+0.009}$ \\
\hline Depth to top (km) & & & & $-0.86 .6^{+0.8}$ \\
\hline Volume changes $\left(\mathrm{km}^{3}\right)$ & & & & $-0.008-0.012^{+0.008}$ \\
\hline
\end{tabular}

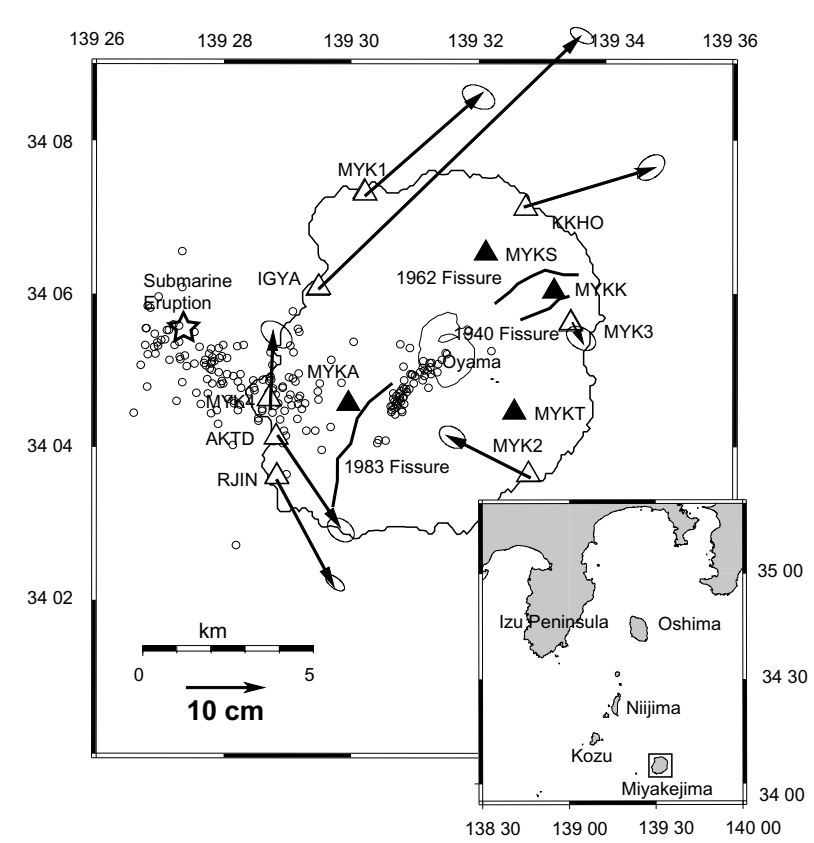

Fig. 1. An overview of the Miyakejima volcano, caldera and location of fissure eruption. Open triangles mark the locations of the dual frequency GPS receivers, solid triangles denote the single frequency GPS receivers. The inset in the lower right shows the location of the depicted region on the map south off Honshu, central Japan. The arrows show the results of the Precise Point Positioning.

quake swarms, until 12:00 27 June 2000, after the submarine eruption. The aim of this paper is to describe the efforts made to understand how rapid deformation developed during the early stage of Miyakejima 2000. A preliminary model is constructed through an inversion analysis.

\section{Data}

Currently, there are 12 continuous GPS sites on Miyakejima, four sites operated by GSI (Geographical Survey Institute), three by ERI (Earthquake Research Institute), one by JHD (Japan Hydrographic Department), and four by NIED (National Research Institute for Earth Science and Disaster Prevention). The GPS receivers operated by NIED are single frequency (L1) receivers. GPS data were collected every 30 sec.

As a preliminary step, we used a fiducial-free precise point-positioning (PPP) strategy of Gipsy/Oasis II (Zum-

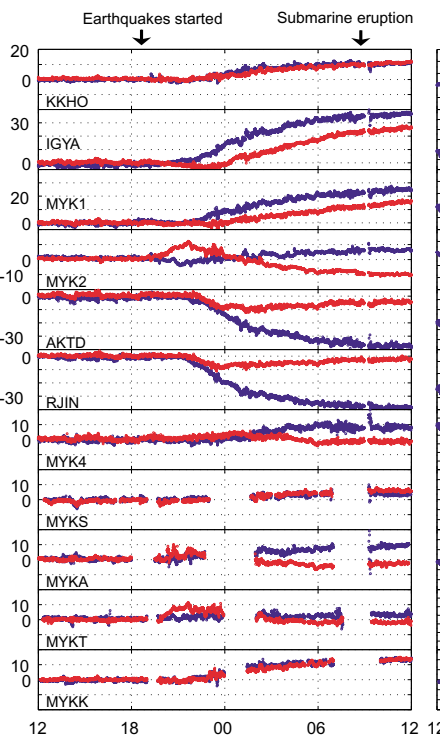

(a)

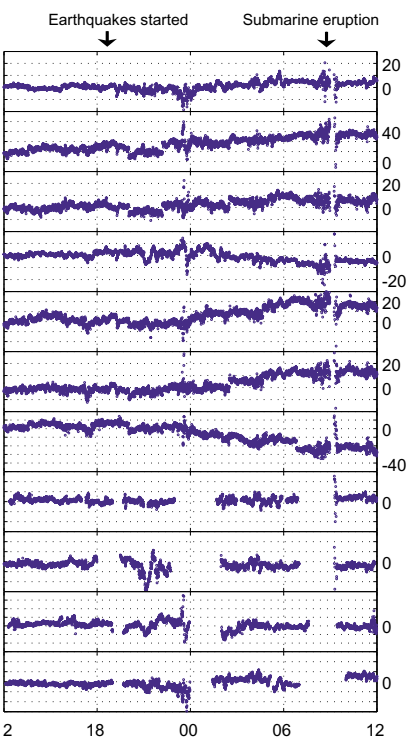

(b)
Fig. 2. Result of Kinematic Analysis. (a) Horizontal component, the blue dots represent north and the red dots represent east. (b) Vertical component.

berge et al., 1997) in order to find a relatively stable station as a fixed station for kinematic processing. The PPP algorithm produces solutions in the ITRF97 reference frame. The time interval of the data is from 9:00-17:00 on 26 June 2000 (before the earthquakes swarm) until 10:00-18:00 on 27 June 2000 (after the submarine eruption). Since the plate motion for 2 days is negligible, we can conclude the observed displacements are mainly caused by the 26-27 June 2000 Miyakejima activity. The result of PPP analysis showed that the MYK3 station has the smallest deformation compared with other GPS sites (Figure 1), so we use this station as a reference station for kinematic analysis.

Next we estimated the evolution of surface deformation using kinematic GPS analysis. The data were processed every $30 \mathrm{sec}$ with Bernese version 4.2 software (Rothacher and Mervart, 2001) using pseudo-kinematic coordinate estimation sequence that includes: (1) cycle-slip screening and outlier removal using ionosphere-free linear combination (L3) double-difference phase residuals; (2) ambiguity resolution using wide-lane (L5) and then L3 single differences. A simi- 
(a)

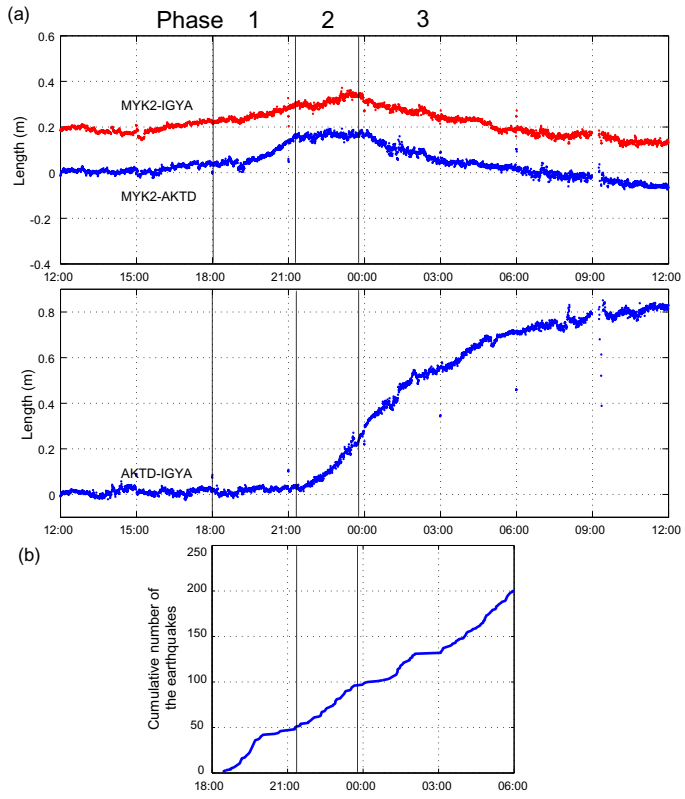

Fig. 3. (a) Horizontal distance changes, from MYK2-AKTD, MYK2-IGYA, and AKTD-IGYA. (b) Cumulative number of estimated earthquakes. The seismic data was not analyzed after 6:00 on 27 June (Sakai, 2001)

lar iterative procedure without linear combination (L3 or L5) was also implemented to the L1 GPS stations. A limiting factor is the number of unknown parameters, since we have to determine a new set of coordinates for each epoch. To reduce the number of coordinate sets, after fixing L5 ambiguities, we introduce the estimated ambiguity in a subsequent solution and use an observation window $(8 \mathrm{hr})$ to obtain the epoch-by-epoch coordinates.

From the time series of the kinematic GPS analysis (Fig. 2), we found the following features: (1) The first rapid ground deformation in the Miyakejima volcano started at MYK2 around 18:30 on 26 June, and it was almost simultaneous with the earthquake swarms (Sakai et al., 2001). (2) The maximum horizontal displacements reached $40 \mathrm{~cm}$ within $18 \mathrm{hr}$ from 18:00 on 26 June. It is interesting to note that the maximum subsidence and uplift were nearly $40 \mathrm{~cm}$ at MYK4 and nearly $20 \mathrm{~cm}$ AKTD, respectively, although the distance between these two sites is less than $1 \mathrm{~km}$. (3) After 21:30 on 26 June, the site displacements in MYK2 and
MYKT turned from eastward to westward and no significant deformation was observed at other GPS sites. (4) From 23:30 on 26 June, the displacement rate increased gradually at the GPS sites in the western part of Miyakejima as the seismicity migrated and approached the west coast. The displacements continued at this rate until 6:00 27 June, some 3 hours before the submarine eruption occurred off the west coast.

\section{Modeling}

In order to interpret the observed displacement, we estimated the surface deformation assuming simple dislocations (Okada, 1992) and point sources of volume change (Mogi, 1958), in a homogeneous elastic half-space. Nonlinear optimization using a genetic algorithm (Goldberg, 1989) was used to find the best-fitting source geometry. The model uncertainties were calculated using methods based on the $\mathrm{F}$ statistics (Murray et al., 1996). There are two key points to consider in modeling. First, since the progress of rapid deformation seems to be strongly correlated with the earthquake swarm activity, we assume that the sources of rapid deformation and of seismic events are identical. A cumulative number of estimated earthquakes from 18:00 on 26 June, to 06:00 on 27 June are plotted in Fig. 3(b). Rubin and Gillard (1998) explained that swarms of earthquakes can occur because of stress concentrations near a dike tip. This implies that we can confine the positions of the dike to the locations of earthquake swarms. Second, we assume that the changes in deformation patterns at 21:30 and 23:30 and also the migration of seismicity faithfully records the evolution of the dikes. On the basis of those considerations, we divided the 26-27 June 2000 activity into three phases.

\subsection{Phase 1. From 18:00-21:30 on 26 June 2000}

At this phase, $10 \mathrm{~cm}$ eastward displacement was observed at MYK2 and MYKT, while other GPS sites showed insignificant deformation activity. The epicenters of the earthquake swarms were confined beneath the Oyama summit. The earthquake distribution shows a linear trend in the SW direction from Oyama at a depth of less than $3 \mathrm{~km}$. Figure 3(a) shows an extension of MYK2-AKTD and MYK2IGYA while no significant distance change was seen between IGYA and AKTD. The cumulative number of the earthquakes increased rapidly from 18:30 to 22:00 (Fig. 3(b)). These local ground deformations and shallow earthquakes suggest that magma was intruding south of the summit crater

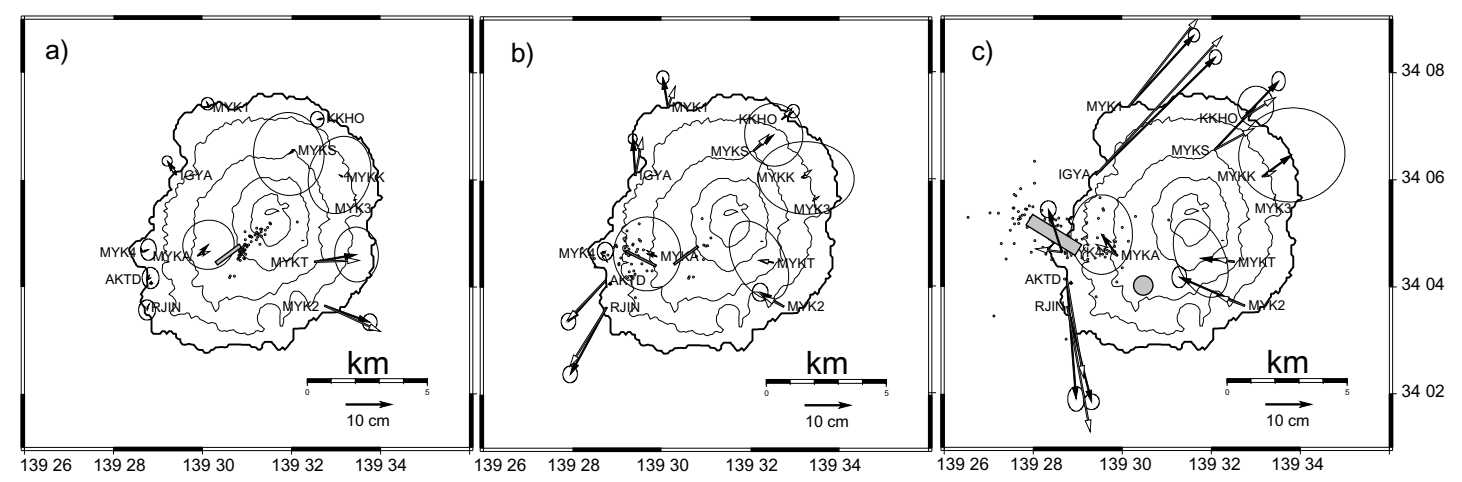

Fig. 4. Observed and predicted deformation from the 26-27 June 2000 Miyakejima activity. Black vectors depict GPS observation, white vector are model predictions. (a) Phase 1, (b) Phase 2, (c) Phase 3. 
at a shallow depth. We attempted to model the deformation at phase 1 with a single dike source near the Oyama crater, to simulate the westward displacements at MYK2 and MYKT. A NE-SW trending dike located very close to the 1983 fissure fits the local extension at MYK2 and MYKT (Fig. 4(a), Table 1).

\subsection{Phase 2. From 21:30-23:30 on 26 June 2000}

During this time interval, the earthquake epicenters migrated and approached MYK4 on the west coast. The displacements observed at MYK2 and MYKT changed to westward at 21:30. The SW displacements over $20 \mathrm{~cm}$ were detected at AKTD and RJIN. The horizontal displacement polarity between MYK4 and AKTD implies the existence of a dike intrusion. The opening of the dike across the MYK4 station also shown in the change in distance between IGYA and AKTD (Fig. 3(a)), began at almost the same time as the seismicity migrated to the west coast. The rate of extension rate was $9 \mathrm{~cm} / \mathrm{hr}$ and decreased with time. We attempted to model the deformation with a single dike located near the west coast. The NW-SE trending dike explains the observed NW and SW extension in the western part of Miyakejima but could not explain the westward displacements at MYK2 and MYKT. We increased the complexity of the model and divided it into two dikes in the inversion. The two-dikes scenario includes a NW-SE trending dike near the west coast and the closing of phase 1 dike (Fig. 4(b), Table 1).

\subsection{Phase 3. From 23:30-09:00 on 27 June 2000}

Horizontal displacements of more than $10 \mathrm{~cm}$ were observed at all GPS sites during this phase. Significant NE motions were detected at the sites in the northern part and SW motions were detected in the south. Moreover, relative subsidence and uplift occurred at MYK4 and AKTD stations, respectively. Earthquake epicenters extended northwest from the west coast. They were located beneath the subsidence area detected by GPS measurements. The continuous shortening between MYK2-AKTD and MYK2 presents strong evidence of a deflation source in the area between MYK2 and AKTD. We modeled the deformation during phase 3 with a single dike near the west coast and a deflation source located to the southwest of the Oyama crater (Fig. 4(c), Table 1). The deflation source simulated the subsidence at MYK2.

\section{Discussion and Conclusion}

The estimated location of dike 1 seems to occupy preexisting fractures created by the 1983 eruption. The volume of this dike decreased $50 \%$ at phase 2 , as dike 2 intruded beneath the west coast. During phase 3, dike 2 propagated laterally (dike 3 ) off the west coast and a deflation of the spherical source was estimated to the southwest of the Oyama crater. The existence of a spherical source deflation was confirmed by Furuya et al. (2001) from the observation of gravity changes.

The volume of magma squeezed from dike 1 was smaller than the volume of the newly intruded dikes. Furthermore, dike 3 was significantly larger than dike 2 , suggesting that a deep magma source supplied the magma to dike 3. Slightly before the submarine eruption at 9:00 on 27 June 2000, the dike grew to $39.5 \times 10^{-3} \mathrm{~km}^{3}$ and spherical source deflated by $6.38 \times 10^{-3} \mathrm{~km}^{3}$. The volume of the erupted materials $(5$ $\times 10^{-6} \mathrm{~km}^{3}$ ) (Shirao et al., 2000), was significantly smaller than the volume of the intruded magma. This suggests that most of the intruded magma migrated further to the west.

Finally, we concluded that kinematic GPS analysis captured the fast developing deformation event of the Miyakejima volcano on 26 June 2000. A spatio and temporal evolution of propagating dikes need to be estimated to reveal quantitative information about the volcanic plumbing systems which is left for further study.

Acknowledgments. We are grateful to the Geographical Survey Institute (GSI) for providing the GPS data. Comments and suggestions by Shigeo Yoshida were helpful in improving this manuscript. We thank the two anonymous referees for some useful suggestions.

\section{References}

Furuya et al., Caldera formation process during the Miyakejima 2000 volcanic activity detected by spatio-temporal gravity changes, Journal of $G e$ ography, 110(2), 217-225, 2001.

Goldberg, D. E., Genetic Algorithms in Search, Optimization, and Machine Learning, 401 pp., Addison Wesley, Reading, Ma., 1989.

Japan Meteorological Agency (JMA), Recent seismic activity in the Miyakejima and Niijima-Kozushima region, Japan, the largest earthquake swarm ever recorded, Earth Planets Space, 52(8), i-viii, 2000.

Kaidzu, M., T. Nishimura, M. Murakami, S. Ozawa, T. Sagiya, H. Yarai, and T. Imakiire, Crustal deformation associated with crustal activities in the northern Izu-islands area during the summer, 2000, Earth Planets Space, 52(8), ix-xviii, 2000.

Kariya, S., F. Kimata, H. Watanabe, J. Oikawa, and T. Matsushima, Ground deformation inferred from GPS observation in Miyake, 94th Meeting, Progr. Abst. Geod. Soc. Jpn, 2, 85-86, 2000 (in Japanese).

Mogi, K., Relation between the eruptions of various volcanoes and the deformations of the ground surfaces around them, Bull. Earthq. Res. Inst. Tokyo, 36, 99-134, 1958

Murray, M. H., G. Marshall, M. Lisowski, and R. Stein, The 1992 M=7 Cape Mendicino, California earthquake: Coseismic deformation at the south end of the Cascadia megatrust, J. Geophys. Res., 1001, 17,70717,725, 1996.

Nishimura, T., S. Ozawa, M. Murakami, T. Sagiya, T. Tada, M. Kaidzu, M Ukawa, Crustal deformation caused by magma migration in the northern Izu Islands, Japan, Geophys. Res. Lett., 28, 3745-3748, 2001.

Oikawa, J. and Observation Group of Miyakejima, Ground deformation associated with the 2000 magma intrusion under Miyakejima volcano inferred from the observation with a dense GPS network, Progr. Abst. Volcanol. Soc. Jpn., 2, 7, 2000.

Okada, Y., Internal deformation due to shear and tensile faults in a halfspace, Bull. Seismol. Soc. Am., 82, 1018-1040, 1992.

Rothacher, M. and L. Mervart, Bernese GPS Software Version 4.2., Astronomical Institute University of Berne, 515 pp., 2001.

Rubin, A. M. and D. Gillard, Dike-induced earthquakes: Theoretical considerations, J. Geophys. Res., 103, 10,017-10,030, 1998.

Sakai, S. et al., Hypocenter distribution in and around Izu island in 2000 , Journal of Geography, 110(2), 145-155, 2001,

Shirao, M. et al., Submarine observation of the undersea craters in the Miyakejima 2000 eruption, Progr. Abst. Volcanol. Soc. Jpn., 5, 2000. (Abstract in Japanese)

Tada, Y. and K. Nakamura, Inflation-deflation related with the 1983 eruption of Miyakejima Volcano, Japan, Bull. Volcanol. Soc. Jpn., 43, 149-166, 1988.

Tsukui, M., K. Niihori, Y. Kawanabe, and Y. Suzuki, Stratigraphy and Formation of Miyakejima Volcano, Journal of Geography, 110(2), 156167, 2001.

Yamaoka, K., F. Kimata, N. Fujii, T. Kubo, K. Takai, T. Kato, T. Tabei, and S. Nakao, Long-lasting dike intrusion causing large crustal deformation and active earthquake swarm in Izu volcanic islands, Japan, Eos, Transaction $A G U, \mathbf{8 1}, \mathrm{F} 1260,2001$.

Zumberge, J. F., M. B. Heflin, D. C. Jefferson, M. M. Watkins, and F. H Webb, Precise point positioning for the efficient and robust analysis of GPS data from large networks, J. Geophys. Res., 102, 5005-5017, 1997.

M. Irwan (e-mail: irwan@seis.nagoya-u.ac.jp), F. Kimata, N. Fujii, S. Nakao, H. Watanabe, S. Sakai, M. Ukawa, E. Fujita, and K. Kawai 